\section{Discussion}

It has been quite definitely established that progestogenoestrogen oral contraception is very effective with certain recognized but not serious side-effects. Our more recent efforts, and those of most other investigators of these compounds, have taken two major directions: (1) a search for better and lowerdosage products; (2) a detailed investigation of the possible long-term effects of these compounds on various organs and body functions, and the determination of the safety, or lack of safety, of many years of consistent use by the same individual.

Since most women now using these products generally take them for family-planning purposes rather than to avoid any further pregnancies, data on long-term continuous use are not easy to obtain. In our clinic the number of women who have used any of our oral contraceptive preparations for over five years continuously is less than 300 , and our studies, with those of Pincus, constitute the longest investigations of this form of contraception. Therefore the total number of continuous users for over five years anywhere is likely to be very limited. It is important that long-term data about continuous use be obtained, because, as this form of contraception is being employed more and more by younger women, we will have millions who may complete their families between the ages of 25 and 30, and they will be depending on the continuous use of these products for another 15 to 20 years.

The detailed blood-chemistry studies we have referred to in this report provide one method of obtaining needed information regarding safety. One problem in obtaining this type of information is that certain abnormalities may be found, and they are not necessarily suggestive of pathology. This may hold particularly true, for example, for such changes as elevations in protein-bound iodine. One would be rash, I believe, in deducing a state of hyperthyroidism because the proteinbound iodine in a patient exceeded the usual normal limit of $8 \mu \mathrm{g} . / 100 \mathrm{ml}$. We therefore have to attempt to correlate any changes in chemical findings with the overall physiological alterations occurring during use of the oral contraceptives. This task of obtaining the data, finding suitable controls, and making the necessary correlation is not an easy one. We would like to extend our thyroid-function tests to those studies employing radioactive material, but this presents a problem when pregnant "controls" are used.
We are currently also finding stumbling-blocks in discovering suitable tests for adrenocortical function that can be employed readily in pregnant patients, with no medical or medico-legal risk. Fortunately, the reputable pharmaceutical manufacturers involved with these preparations, as well as various research organizations, are anxious to obtain all the information possible, and there is little problem regarding support in this respect. It is likely that, despite the obvious obstacles, the next few years will bring about an elucidation of the manifold effects that progestogen-oestrogen contraception may have. So far, we know they are extremely effective and we have no definite evidence of serious toxicity. We also know that it requires very small amounts of these agents to provide efficacious contraception. In the case of norethisterone the dose is now down to $2 \mathrm{mg}$. (with $0.1 \mathrm{mg}$. of mestranol), and the minimal effective dose may even be lower, a matter we are now in the process of investigating.

\section{Summary}

A brief review of eight years' study of oral contraception is given. Reference is made to detailed blood-studies carried out on patients using various preparations, and a discussion of certain of the findings is presented. In general, while some chemical factors were altered, it is very possible that these are not evidence of a pathological change, but, rather, may be attributable to the pseudopregnancy state. These studies are being continued and expanded.

An analysis of over three years' study of the 2-mg. norethisterone product is also presented. In 6,455 cycles of use by 435 patients side-effects were minimal and there were no pregnancies.

\section{REFERENCES}

Goldfarb, A. F. (1964). In Advances in the Treatment of Menstrual Dysfunction. Lea and Febiger, Philadelphia.

Henstell, H. (1963). Proceedings of Conference on Thrombophlebitis. Chicago, III. Searle.

Proceedings 4th International Planned Parenthood Congress, Singapore, Feb. 1963.

Samuels, A., and Lepowsky, F. (1963). Int. 7. Fertil., 8, 665.

Tyler, E. T. (1963). I. Amer. med. Ass., 185, 131.

(1964). Ibid., 187, 562.

and Olson, H. J. (1958). Ann. N.Y. Acad. Sci., 71, 704.

- (1959). F. Amer. med. Ass., 169, 1843.

- Gotlib, M., Levin, M., and Behne, D. (1964). Clin. Med., 71, 997.

M. Wolf, L., Finkelstein, R. N. S., Thayer, J., Kaplan, N., Levin, M., and Weintraub, J. (1961). Obstet. and Gynec., 18, 363.

\title{
Use of a Modified Minicoil for Continuous Dialysis
}

\author{
D. J. BLACKMORE,* M.I.BIOL. ; G. MITCHELL, $\dagger$ M.B., CH.B.
}

Brit. med. F., 1964, 2, 847-850

Management of acute renal failure may include the use of artificial kidneys with dialysing areas varying between 0.4 and 3.2 sq.m. to supplement conservative regimes. Dialyses may be carried out at varying intervals, but recent trends have been for earlier and more frequent dialysis.

This preliminary communication presents a report of modifications to a small dialysing apparatus with a dialysis membrane

* Pilot Officer, R.A.F., Research Department, Institute of Pathology and Tropical Medicine. Present address: Department of Pathology, R.A.F. Hospital, Steamer Point, Aden. B.F.P.O. 69

t Squadron Leader, R.A.F., Srecialist in Medicine, Renal Unit, Princess Mary's R.A.F. Hospital, Halton, Aylesbury, Bucks. of viscose cellulose tube $4.4 \mathrm{~cm}$. wide by $5.14 \mathrm{~m}$. long producing a surface area of 0.45 sq. $\mathrm{m}$. marketed under the trade name of Minicoil (Lawson et al., 1962) and of its use in a modified form for continuous dialysis.

The manufacturer's description of the Minicoil includes the following points: "The coil unit is welded into a P.V.C. envelope which assumes an almost spherical form when distended with dialysis fluid ; this ensures an even perfusion of the dialysis membrane without leakage round the periphery of the coil. ... The entire unit is suspended from a moulded hanger via a flap which also serves the purpose of anchoring the constant-level device on one side and the blood filter and air-trap on the other." 
When used in this manner the junction between the coil cover and the suspensory system ruptured on several occasions so that prolonged use of the apparatus was not possible.

The design of the combined filter and air-trap had several disadvantages: (a) should obstruction of the filter occur it was necessary to replace the whole apparatus ; $(b)$ visual assessment of blood-flow was difficult ; (c) maintenance of blood level in the trap by repeated puncture of a self-sealing rubber plug was undesirable; and $(d)$ recording outflow pressure by direct connexion of the venous return tubing to a manometer was not regarded as a safe procedure.

When the arterio-venous-pressure difference was insufficient to give adequate flow through the coil, the tubing, as supplied, was not suitable for pumping with either roller or sigmamotor pumps.

Using the Minicoil, Lawson et al. recorded an average bloodflow rate of $100 \mathrm{ml} . / \mathrm{min}$., but we were unable to obtain flow rates above $80 \mathrm{ml} . / \mathrm{min}$. Removal of urea in the dialysing fluid at a rate of $3 \mathrm{~g}$./hour was reported by Lawson et al.; we felt this would be inadequate when treating acute renal failure in patients with blood ureas rising faster than $120 \mathrm{mg} . / 100 \mathrm{ml}$./ $24 \mathrm{hr}$.

The Minicoil has a valuable place in haemodialysis in view of its small size, cheapness, ease of assembly, and versatility ; it was thought that the disadvantages could be overcome by some simple modifications.

\section{Modifications}

Fig. 1 is a photograph of the modified Minicoil. The coil itself is as described by Lawson et al. after removal of the air-trap, venous and arterial tubes, and suspensory system. The tubing from the artery, the air-trap, and the tubing returning blood to the vein are in single sets separately packed and sterilized.

The arterial set consists of a length of light flexible P.V.C. tube with sampling side-arms, self-sealing rubber insert for regional heparinization, pump tubing for use with either sigmamotor or roller pump (sigmamotor pump tubing is illustrated), and a bypass tube should the pump not be required.

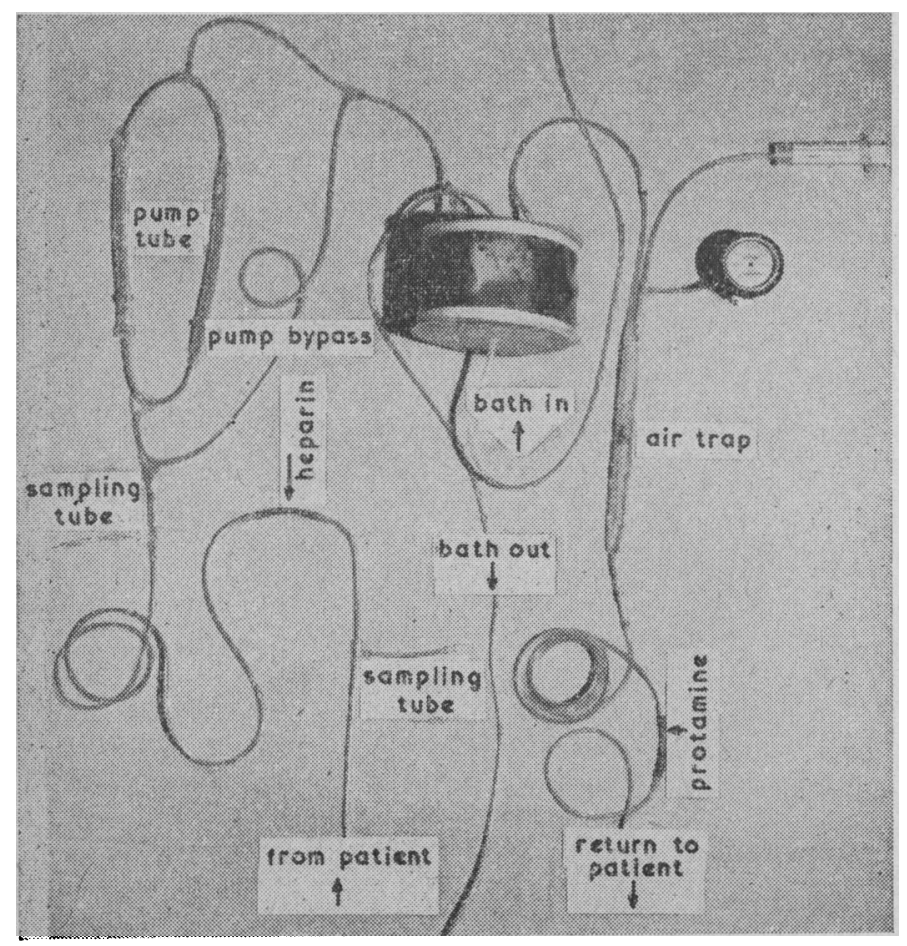

FIG. 1.-Photograph of Minicoil and its modifications.
The combined air-trap and filter consists of a filter fitted with two side-arms, one for a manometer and the other for a syringe to allow adjustment of fluid level. The upper half of the trap contains a plastic float with a rubber to plastic self-sealing hole. If the blood in the trap falls to a level below 1 in. $(2.5 \mathrm{~cm}$.) above the outlet, blood-flow is completely occluded; this prevents air being returned to the patient in case of mishap.

The venous set consists of a simple light flexible P.V.C. tube with a self-sealing rubber insert for infusion of protamine sulphate during regional heparinization.

As noted earlier, the manufacturers recommend that the coil should be allowed to blow up into a spherical form. The total volume of fluid contained by the Minicoil under these conditions is approximately $2.5 \mathrm{l}$.; the weight of this fluid was largely responsible for the tearing of the suspensory system we experienced in our initial trials.

The modified version of the coil has two tubes for the bath circuit; with the outlet tube at a level at least $3 \mathrm{ft}$. $(0.9 \mathrm{~m}$.) below that of the coil the dialysing fluid siphons and the P.V.C. envelope collapses, forming a tighter seal around the periphery of the coil ; the volume of the dialysate dead space is significantly reduced and the coil may be left free-standing.

Reduction in the volume and pressure of the dialysing fluid in the P.V.C. envelope reduces the resistance to the flow of blood through the cellophane tubing. It is believed that the improved efficiency of dialysis to be reported is largely due to the alteration of the dialysing-fluid circuit and the resultant improvement in flow of blood.

The modified coil, arterial set, venous set, and air-trap are colour-coded and connect to the coil with male and female Luer fittings arranged in such a way that the complete dialysing unit can be assembled only in the correct manner.

\section{Results}

Clearance from Aqueous Solutions.-To assess the efficiency of the modifications, two solutions of urea in saline containing $250 \mathrm{mg}$. urea $/ 100 \mathrm{ml}$. and $500 \mathrm{mg}$. urea $/ 100 \mathrm{ml}$. respectively were dialysed against normal saline $(0.9 \mathrm{~g}$. $\mathrm{NaCl} / \mathrm{l}$.). After 30 minutes' equilibration for any given set of bath and bloodflow rates, clearances were determined in triplicate at 15-minute intervals.

Urea Clearance.-Calculation from the data of Lawson et al. gives a blood-urea clearance of $24 \mathrm{ml} . / \mathrm{min}$. from artificial solutions at a blood-flow rate of $100 \mathrm{ml} . / \mathrm{min}$. Fig. 2 presents the blond clearance for changes in bath-flow rate with a constant blood-flow rate of $100 \mathrm{ml} . / \mathrm{min}$. and blood clearances for changes in blood-flow rate with a constant bath-flow rate of $200 \mathrm{ml} . / \mathrm{min}$. It can be seen that at a blood-flow rate of

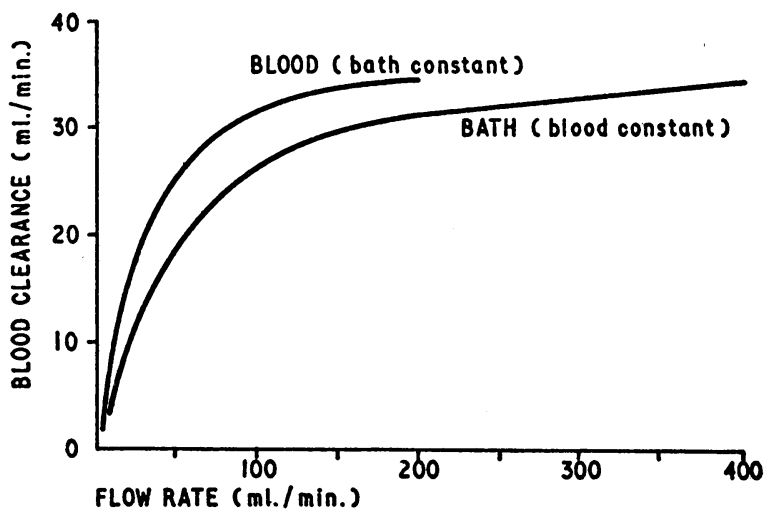

FIG. 2.-Grapb of blood-urea clearance at varying blood-fow rates, with a constant bath-flow rate of $200 \mathrm{ml}$./min., and at varying bath-flow rates, with a constant blood-flow rate of $100 \mathrm{ml}$./min. 
$100 \mathrm{ml} . / \mathrm{min}$. and a bath-flow rate of $200 \mathrm{ml} . / \mathrm{min}$. a clearance of $30 \mathrm{ml} . / \mathrm{min}$. is obtainable.

Removal of Water.-Fig. 3 indicates the rate of removal of water in $\mathrm{ml} . / \mathrm{hr}$. for varying glucose concentrations at a blood-flow rate of $100 \mathrm{ml} . / \mathrm{min}$. Fig. 4 shows the rate of ultrafiltration of water from the blood circuit with changes in pressure measured at the air-trap. The pressures were increased by occluding the venous outlet with a gate clamp.

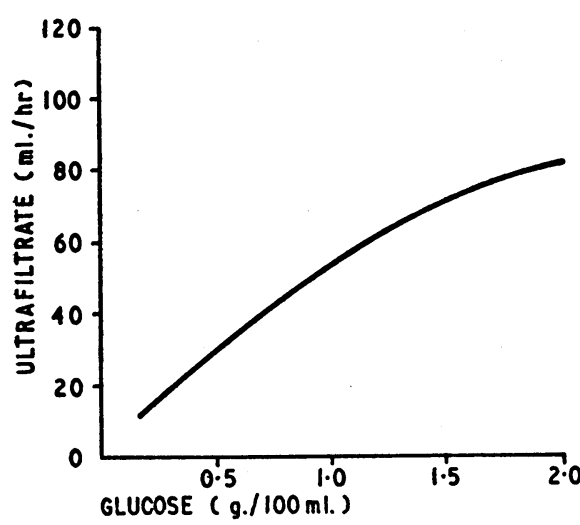

FIG. 3.-Graph showing millilitres of water removed from coil at a blood-flow rate of 100 $\mathrm{ml}$./min., at varying concentrations of glucose in the dialysing fluid.

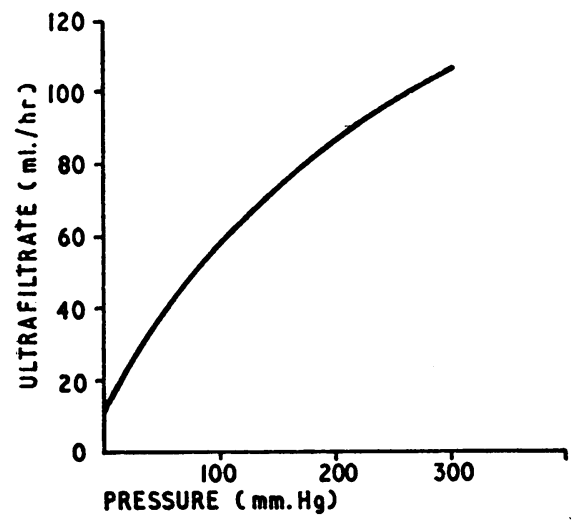
100 from the coil at a blood-flow rate of quired intermittent examination showed severe bilateral pneumonic changes in addition to the direct effects of trauma.

Dialysis was begun when the plasma urea was over $250 \mathrm{mg}$./ $100 \mathrm{ml}$. Blood was pumped at $100 \mathrm{ml} . / \mathrm{min}$. until the plasma urea had fallen to $150 \mathrm{mg} . / 100 \mathrm{ml}$. or below, blood sampling being undertaken at 12-hourly intervals, after which the pump an increase of pressure to $250-300$ $\mathrm{mm}$. $\mathrm{Hg}$ will allow the removal of up to $2,500 \mathrm{ml}$. water per day.

Clinical Experience dialyses have been carried out on seven patients (see Table). Three of the seven patients died, one (Case 2) from the head injury sustained at the time of the accident and one (Case 7) from terminal chronic renal failure. The other patient (Case 3) died after cardiac arrest, which occurred when he pulled out his tracheostomy tube. The original trauma included multiple fractures of the ribs, contusion of the lungs, and a left haemothorax. From the third day of his illness he re-
FIG. 4- Graph showing millilitres of water remeasured in the air trap.

was bypassed. Pumping was started again if the blood-flow rate of 50 to $80 \mathrm{ml} . / \mathrm{min}$. was not sufficient to maintain the plasma urea in the range $150-200 \mathrm{mg} . / 100 \mathrm{ml}$. In practice Cases 1 , 5 , and 6 were dialysed without the pump at night but had periods of pumping during the day. It is considered that when using this apparatus a pump will be required for most patients from time to time.

The case report of one patient is submitted in detail.

Eleven haemoClinical and Biochemical Data on Seven Patients

\begin{tabular}{|c|c|c|c|c|c|c|}
\hline \multirow{2}{*}{$\begin{array}{l}\text { Case } \\
\text { No. }\end{array}$} & \multirow{2}{*}{ Diagnosis } & \multirow{2}{*}{$\begin{array}{c}\text { Duration of } \\
\text { Dialyses }\end{array}$} & \multirow{2}{*}{$\begin{array}{c}\text { Rise in Plasma Urea } \\
\text { in } 24 \text { Hours } \\
\text { Preceding First } \\
\text { Dialysis (mg./100 ml.) }\end{array}$} & \multicolumn{2}{|c|}{ Plasma Urea (mg./100 ml.) } & \multirow{2}{*}{ Result } \\
\hline & & & & Pre-dialysis & Post-dialysis & \\
\hline 1 & $\begin{array}{l}\text { Gunshot wound (R) thigh. } \\
\text { Delayed rupture (R) kidney. } \\
\text { B/K amputation (R) leg }\end{array}$ & $\begin{array}{l}4 \text { days } 4 \frac{1}{2} \text { hours } \\
4 \text { days } 6 \frac{1}{2} \text { hours. } \\
3 \text { days } 11 \text { hours. } \\
20 \text { hours. }\end{array}$ & 150 & $\begin{array}{l}325 \\
220 \\
220 \\
250\end{array}$ & $\begin{array}{r}55 \\
135 \\
130 \\
185\end{array}$ & Recovered \\
\hline 2 & Multiple injuries (road traffic accident) & 2 days 5 hours & 90 & 215 & 185 & Died \\
\hline 3 & Multiple injuries (road traffic accident) & $\begin{array}{l}2 \text { days } 3 ! \text { hours } \\
2 \text { days } 20 \frac{1}{2} \text { hours }\end{array}$ & 125 & $\begin{array}{l}280 \\
250\end{array}$ & $\begin{array}{l}100 \\
210\end{array}$ & Died \\
\hline 4 & Multiple injuries (road traffic accident) & 2 days 12 hours & 105 & 310 & 290 & Recovered \\
\hline 5 & Infectious hepatitis & 3 days 8 hours & 95 & 370 & 75 & Recovered \\
\hline 6 & Diabetic coma & 46 hours & 30 & 350 & 220 & Recovered \\
\hline 7 & $\begin{array}{l}\text { Terminal chronic renal failure. } \\
\text { Hyperkalaemia }\end{array}$ & $9 \frac{1}{4}$ hours & 50 & 490 & 270 & Died \\
\hline
\end{tabular}
1 November 1963, four days after a gunshot wound of the right thigh.

On admission his haemoglobin was $63 \%$ (Haldane), total W.B.C. $13,600 /$ c.mm., blood urea $325 \mathrm{mg} . / 100 \mathrm{ml}$., plasma potassium 9.2 $\mathrm{mEq} / \mathrm{l}$., sodium $118 \mathrm{mEq} / 1$., chloride $76 \mathrm{mEq} / \mathrm{l}$., and bicarbonate $20 \mathrm{mEq} / 1$.

Dialysis was begun two hours after admission. He was connected to the modified Minicoil, using P.V.C. cannulae; a tapered arterial cannula was inserted into the right radial artery and a French gauge-13 cannula returned blood to the right cephalic vein. No anticoagulants were given to the patient ; blood-clotting in the coil was controlled by regional heparinization.

The composition of the dialysing fluid was: deionized water; bicarbonate $36 \mathrm{mEq} / 1$. ; calcium $5 \mathrm{mEq} / 1$. ; magnesium $1.5 \mathrm{mEq} / \mathrm{i}$. ; glucose $800 \mathrm{mg} . / 100 \mathrm{ml}$. for the first two days and for the last 20 hours, otherwise $400 \mathrm{mg} . / 100 \mathrm{ml}$; ; chloride 103-107 mEq/l. (depending on the amount of potassium chloride added) ; potassium, nil for the first two days, thereafter $4.0 \mathrm{mEq} / \mathrm{l}$.; sodium $150 \mathrm{mEq} / 1$. until the patient's plasma reached $140 \mathrm{mEq} / \mathrm{l}$., then reduced to $140 \mathrm{mEq} / 1$. - the extra sodium was added as sodium lactate. Lactic acid was added to adjust the $\mathrm{pH}$ to 7.4 .

Fluids were given to replace amounts lost in urine, fluid faeces, and by ultrafiltration from the Minicoil, plus $400 \mathrm{ml}$. a day allowance for insensible loss. The initial diet was $20 \mathrm{~g}$. of protein per day, and was gradually increased with improvement in the patient's appetite and general condition, so that two weeks after admission he was taking $80 \mathrm{~g}$. of protein per day. The dietary carbohydrate intake was $100 \mathrm{~g}$. initially, increasing to $200 \mathrm{~g}$. after 10 days. During dialysis an additional $300-450 \mathrm{~g}$. of glucose per day was absorbed from the dialysing fluid-calculated from analysis of glucose concentration in blood leaving and entering the coil and observed blood-flow rates.

The first dialysis lasted $100 \frac{1}{4}$ hours and was discontinued when the patient was taken to the operating-theatre. Signs of increasing internal haemorrhage had developed over the previous 12 hours, and at laparotomy a large retroperitoneal haematoma was discovered. This was evacuated and a small linear laceration was seen in the lower pole of the right kidney.

Dialysis was restarted on the day after the laparotomy and carried on for 102 hours, ceasing when the patient went to the operating-theatre for a below-knee amputation of the right leg. Ischaemic necrosis of the leg had developed and was adversely affecting the patient's general condition and increasing protein breakdown. For the two days preceding the amputation the concentration of urea in the dialysing fluid varied between 30 and $40 \mathrm{mg}$. $/ 100 \mathrm{ml}$. and the bath-flow rate was $250 \mathrm{ml} . / \mathrm{min}$. During
An Army private aged 20 was admitted to the renal unit on 
this time the patient's plasma urea fell from 165 to $135 \mathrm{mg} . / 100 \mathrm{ml}$, with a blood-flow rate of $100 \mathrm{ml} . / \mathrm{min}$.

Dialysis was restarted the next day, lasted 83 hours, then stopped for 41 hours, and a final 20-hour dialysis was undertaken at the onset of the diuretic phase.

Daily blood urea, plasma potassium, and urine outputs are charted in Fig. 5.

Daily weight changes were noted. The average loss of weight in patients with acute renal failure is 0.2 to $0.3 \mathrm{~kg} . /$ day. This rate of loss occurred in the patient, with a fluid intake of 1,500 $2,000 \mathrm{ml} . /$ day in excess of output compared with the 400-500 ml./day usually allowed in patients not being dialysed. This suggests that $1,000-1,500 \mathrm{ml}$. of water were lost daily by ultrafiltration. As the patient was not clinically overhydrated no attempt was made to increase the rate of water loss by increasing the resistance to venous outflow. Nor was this done in any of the other patients, so in vivo measurements are required to confirm in vitro experiments on water removal.

\section{Discussion}

Dialyses are carried out for varying lengths of time, depending on the clearance of the apparatus and factors such as the initial level of the blood urea. When dialysis is used intermittently, periods commonly employed are four and a half hours for rotating drum and six hours for Kolff twin-coil "artificial kidneys." The modified Minicoil would be correspondingly employed for 24 to 30 hours. However, in the present cases dialysis was at times continued for much longer periods in an attempt not only to lower the blood urea and correct plasma electrolyte abnormalities but to maintain the biochemical improvement.

Over 400 dialyses have been carried out in this unit using a Kolff twin-coil artificial kidney. Advantages of the Minicoil compared with this well-tried apparatus appear to be: (a) blood is not required for priming-normal $(0.9 \%)$ saline was used, the volume ranging from 250 to $300 \mathrm{ml}$.; (b) maintenance of the lowered blood urea and corrected plasma electrolytes allows surgical procedures to be undertaken at any time during the period of acute renal failure with less risk than in patients being infrequently intermittently haemodialysed; and $(c)$ the slower clearance of urea reduces the tendency to development of the dialysis disequilibrium syndrome-a feature of uraemia and rapid clearance of urea by dialysis (Kennedy et al., 1962, 1963 ; Cowie et al., 1962).

However, the use of the modified Minicoil for continuous dialysis has produced several problems:

Staffing.-Lack of inbuilt safety devices has necessitated continuous supervision by highly trained medical, technical, and nursing staff. Under these circumstances this method of treatment could not be used routinely in the treatment of acute renal failure.

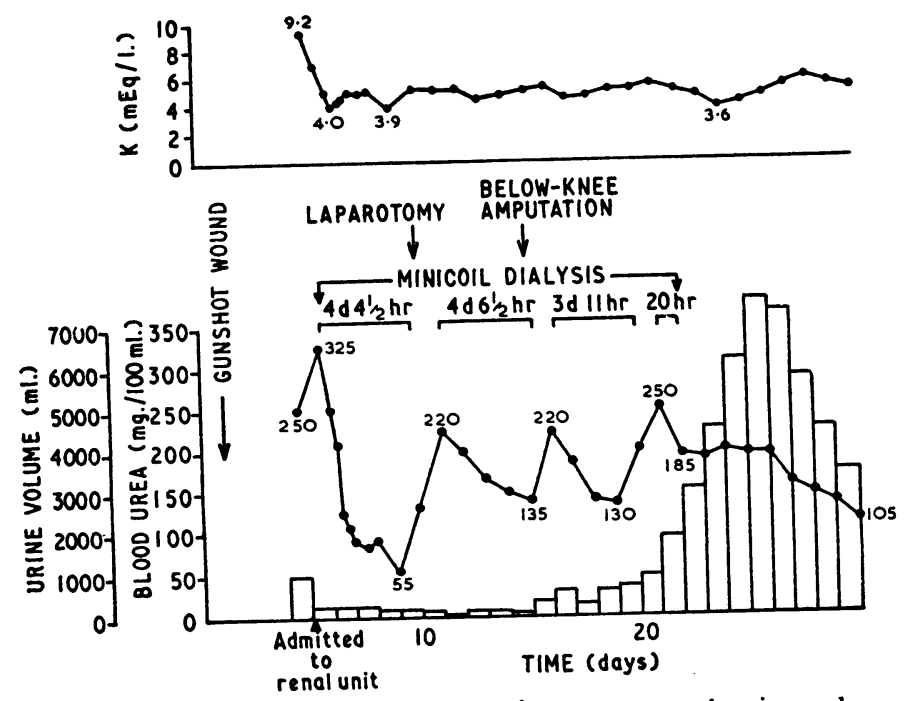

FIG. 5.-Case 1. Plasma potassium, plasma urea, and urine volume during period of acute renal failure.
Investigations are being directed to the development and production of a "fail-safe" pumping unit which can be used for prolonged periods and managed largely by nursing staff provided a doctor is readily available.

Regional Heparinization.-Anticoagulation may be controlled with continuous or intermittent heparin infusion, or regional heparinization may be instituted, heparin being used to prevent clotting in the coil and protamine sulphate to neutralize the heparin before return of blood to the patient. Continuous regional heparinization in our hands has required half-hourly whole-bloodclotting times on samples from the patient and the coil, as batches of heparin and protamine sulphate have varied in potency.

Efficiency of Dialysis.-After 48 hours of continuous dialysis in Case 3 the concentration of urea in the dialysis fluid fell and the plasma urca rose with blood-flow and bath-flow rates remaining steady. After changing the coil the concentration of urea in the dialysis fluid rose and the plasma urea fell. It is suggested that the concentration of urea in the dialysing fluid should be determined 12-hourly to detect any loss of efficiency.

There are several other aspects in the use of continuous haemodialysis with a modified Minicoil worthy of comment.

Dialysing Fluid.-(1) Temperature: The dialysing fluid is made up in 50-1. batches and stored in polythene aspirator bottles at room temperature and passed through a water-bath at $40^{\circ} \mathrm{C}$. before passage through the coil. (2) Bacteriological Control: Twice-daily samples of bath fluid running to waste were taken and were negative on culture. Daily blood cultures from the patient were negative. However, in view of other workers' experience of the tendency to growth of bacteria in the dialysing fluid more intensive investigation of this problem is required.

Results.-It is appreciated that this series is not comparable with that of Teschan et al. (1960) using intermittent daily haemodialysis nor that of Murray et al. (1961) employing continuous haemodialysis with a Kiil dialyser. However, it is felt that results from continuous haemodialysis using a modified Minicoil in this small series, and with our limited experience, justify further use in patients with severe acute renal failure.

\section{Summary}

Modifications to a small haemodialysing apparatus (Minicoil) which offset certain disadvantages of the original and improve its efficiency are described. In vitro studies of urea clearance from saline, and the removal of water by varying the bath glucose concentration or the outflow pressure from the coil, are recorded.

Clinical experience of 11 continuous haemodialyses on seven patients is reviewed, one case being presented in detail. Some of the problems of this technique and its advantages in hypercatabolic renal failure are discussed.

A fail-safe pumping unit for use with the Minicoil is being developed, and should reduce the staffing and management problems.

We wish to thank Air Commodore R. C. Jackson, Consultant in Medicine, for his help and encouragement. We are indebted to Air Commodore W. P. Stamm, Senior Consultant in Pathology, for encouragement and guidance in preparation of this paper. We are grateful for the skill and co-operation of the nursing staff of the Renal Unit, Princess Mary's Rnyal Air Force Hospital, and for the assistance of the staff of the Royal Air Force Institute of Pathology and Tropical Medicine. The assistance of Capon Heaton and Co. Ltd. has been much appreciated. We should like to thank the Director-General of Royal Air Force Medical Services for permission to publish.

REFERENCES

Cowie, J., Lambie, A. T., and Robson, J. S. (1962). Clin. Sci., 23, 397. Cowie, J., Lambie, A. T., and Robson, J. S. (1962) (1962). Lancet, 1, 410. Kennedy, A. C., Linton, A. L., and Eaton, (1963). (1bid., 1, 408.

Lawe, R. G., and Renfrew, Dawson-Edwards, P., and Dukes, D. C. (1962). Ibid., 2, 23 .

Murray, J. S., Hegstrom, R. M., Pendras, J. P., Burnell, J. M., and Scribner, B. H. (1961). Trans. Amer. Soc. Art. Int. Org., 7, 94. Teschan, P. E., Bax:er, C. R., O'Brien, T. F., Freyhof, J. N., and Hall, W. H. (1960). Ann. intern. Med., 53, 992. 